\title{
Pequena História da Fotografia nas Redes Sociais
}

\author{
Wagner Souza e Silva \& Raul Ernesto Pereira \\ Universidade de São Paulo \\ E-mail: wasosi@gmail.com/raul.pereira@outlook.com
}

\begin{abstract}
Resumo
Servindo-se de uma aproximação similar à que Wal- promovidas pelo numérico nas últimas duas décater Benjamin estabelece em seu Pequena história da das, as quais vêm definindo os primeiros movimenfotografia, texto produzido próximo ao centenário da tos de uma prática fotográfica inserida numa nova prática fotográfica, o ensaio aqui proposto buscará dinâmica de produção e compartilhamento, que enexplorar a recente trajetória da fotografia associada tendemos possuir importância e ineditismo similares às redes sociais, neste momento próximo ao seu bi- aos primeiros anos da fotografia no século XIX, os centenário. Apesar de pequeno em termos de tempo, quais, para Benjamin, representaram a essência da o período aqui abordado é grandioso em termos de fotografia.
\end{abstract} impacto, em vista das reconfigurações tecnológicas

Palavras-chave: história da fotografia; redes sociais; Walter Benjamin.

\section{Introdução}

$\mathrm{O}$

TEXTO Pequena história da fotografia, de Walter Benjamin (1994), que data originalmente de 1931, foi redigido num momento em que a técnica completava aproximadamente o seu primeiro centenário ${ }^{1}$. Benjamin considerava este distanciamento temporal com a origem da técnica fotográfica como um componente fundamental para a percepção do primeiro decênio da fotografia como o período de seu apogeu. Isto é, tal distanciamento teria sido importante no sentido de demonstrar o valor dos primeiros movimentos em torno da nova tecnologia, que estavam mais próximos das "artes da feira"do que da indústria (p.92), em que as primeiras fotografias, "belas e inabordáveis"(p.108), tinham o potencial de evidenciar questões históricas e filosóficas que não teriam sido consideradas por décadas.

Ao contrário dos quase cem anos de distanciamento de Benjamin, este pequeno texto aqui proposto remontaria, ao máximo, às duas décadas mais recentes da história da fotografia. Tal

Data de submissão: 03-11-2017. Data de aprovação: 06-03-2018.

A Revista Estudos em Comunicação é financiada por Fundos FEDER através do Programa Operacional Factores de Competitividade - COMPETE e por Fundos Nacionais através da FCT - Fundação para a Ciência e a Tecnologia no âmbito do projeto Comunicação, Filosofia e Humanidades (LabCom.IFP) UID/CCI/00661/2013.
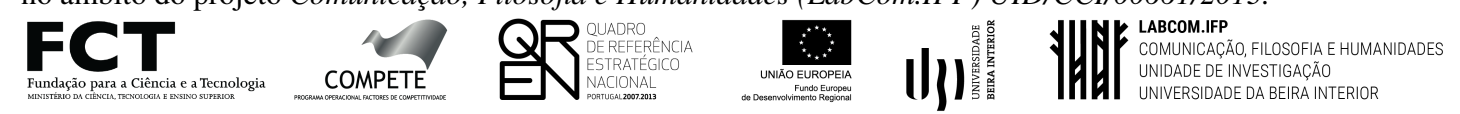

1. Atribui-se ao ano de 1839 o surgimento da fotografia, considerando-se a divulgação do processo de Daguerre, mas cabe aqui lembrar que a imagem heliográfica de Niépce, "Point du vue du Gras", que é comumente registrada como a fotografia mais antiga, data provavelmente de 1826 ou 1827. 
como será detalhado mais à frente, podemos considerar o final dos anos 1990 como o período inicial de consolidação da fotografia digital, bem como da popularização da web; também foi durante os últimos 20 anos que surgiram tanto a rede social mais popular atualmente, o Facebook, em 2004, quanto a "câmera fotográfica"mais vendida da história da fotografia ${ }^{2}$, o iPhone, em 2007, cabendo também observar o surgimento das redes sociais do Instagram (2010) e Snapchat (2013).

Tal período se insere num contexto tão ou mais inquietante que aquele que circundou não só o período do daguerreótipo (1839-1851), mas também aquele que estabeleceu os alicerces para a sua consolidação industrial, por George Eastman e a Kodak (a partir de 1888), visto que constantes reconfigurações tecnológicas vêm refinando os ambientes de produção e circulação da fotografia em sua configuração digital, o que promoveu um crescimento vertiginoso e exponencial da presença de sua prática no cotidiano.

É certo que também estamos próximos do bicentenário da prática fotográfica e propomos, assim, observar como estas inovações relativamente recentes, ao mesmo tempo em que reforçam sua tradição, também expandem o campo fotográfico, coisa que ficou gritante no momento em que a associação entre fotografia e redes sociais passou a definir fortemente o contexto imagético.

A pretensão aqui de se propor um pequeno esboço de história para algo tão recente, e em andamento, é motivada por tese similar à de Benjamin: estamos atribuindo a este movimento atual de associação da fotografia com as redes sociais a mesma importância que o autor alemão atribuiu aos primeiros movimentos da fotografia no século XIX. Ainda que as condições de temporalidade de abordagem se dêem de maneira distintas, há de se considerar que estes últimos 20 anos da fotografia, apesar de representarem um período relativamente pequeno, sugerem grandes impactos para incrementar ainda mais as questões em torno do tema, permitindo, talvez, que não seja necessário nos distanciarmos outros novos cem anos para notá-los como tal.

\section{Da câmera escura à tela iluminada}

Dada a complexidade estrutural das tecnologias envolvidas na prática fotográfica atual, uma eventual cronologia desta técnica não pode mais ser apontada sem se levar em conta algumas pontuações de outras histórias, como a da internet (protocolos, redes sociais, etc.), do audiovisual (cinema, vídeo, TV, etc.) ou da informática (softwares, hardwares, etc.). Benjamin, a partir do discurso de François Arago de 1839, e com o intuito de demonstrar quão irrelevante era a discussão sobre a fotografia ser arte ou não, exaltou o "verdadeiro alcance da invenção", que, para ele, residia no fato de a fotografia ser um instrumento a serviço de "todos os aspectos da atividade humana"(Benjamin, 1994, pp.92-93). Tal vocação da fotografia, num certo sentido, é reforçada quando observamos este incremento em sua cronologia, verificando, assim, seu potencial para ampliar o universo que é mobilizado ao seu redor.

Quando observamos que a película perfurada de 35mm, que, no final do século XIX, foi criada primeiramente para servir ao cinema, também passaria a ocupar uma posição central no universo

2. Siqueira, E. iPhone é o grande campeão de vendas. Disponível em http://cbn.globoradio.globo.com/ comentaristas/ethevaldo-siqueira/2016/08/03/IPHONE-E-O-GRANDE-CAMPEAO-DE-VENDAS.htm. Acesso em 12 abr. 2017. 
das imagens estáticas (inicialmente por meio das câmeras Leica e posteriormente como um importante padrão para a comercialização em larga escala da fotografia), ou que as câmeras fotográficas digitais serviram-se de uma estrutura criada inicialmente para a captura do vídeo (os sensores CMOS e CCD, na década de 1970), o qual, por sua vez, surgiu a partir de uma busca pela eletronificação da imagem em movimento, com o objetivo de propulsionar as interseções entre TV e cinema, vemos, na verdade, que a hibridização tecnológica que assistimos nos dias que correm, portanto, nada mais é do que o desdobramento natural de um direcionamento da produção de imagem organizada por um mesmo sistema tecnológico estruturante.

De fato, tendo o seu funcionamento baseado nos sistemas da perspectiva e da câmera escura, a fotografia não só deu origem à estruturação de outras formas de imagem, como também germinou um sistema de produção de informação que, em muitos aspectos, também é uma derivação de sua estrutura $^{3}$, coisa que se consagra a partir da importância contemporânea das telas como canais de acesso (ainda que seja notável o fato de a fotografia ter tentado, até um último momento, por meio de um pool das principais empresas do ramo, resistir à sua total eletronificação, coisa que ocorreu com a pífia tentativa, em 1996, de instalação do sistema APS - Advanced Photo System, que usava a película aliada a uma banda magnética com dados para facilitar o diálogo entre as câmeras e os laboratórios de revelação e cópias).

O que Benjamin notara sobre a tendência de a câmera se tornar cada vez menor, "cada vez mais apta a captar imagens efêmeras e secretas", ou mesmo sobre a "irreversível necessidade de possuir um objeto de tão perto quanto possível, na imagem, ou melhor, na sua reprodução"(Benjamin, 1994, pp.101-107), já demonstrava a ideia de um direcionamento da tecnologia fotográfica em busca da miniaturização e portabilidade do artefato imagético: observando-se a trajetória tecnológica das câmeras, isto é, dos grandes aparatos dos primeiros processos (daguerreótipo, calótipo, colódio úmido), passando pelas inúmeras câmeras portáteis (Leica, câmeras Kodak, etc.), além daquelas para a produção de instantâneos (polaroides), vemos cada vez mais um refinamento tecnológico em favor da imagem e da supressão da câmera, o que é coroado pela assunção da tela, que agora não é mais somente um terminal de acesso ao universo da informação, mas a própria estrutura de produção da imagem fotográfica, tal como vemos ocorrer exemplarmente nos gadgets contemporâneos.

O smartphones concretizam a ideia da portabilidade e intimidade com a imagem, e são o resultado de um crescente aprimoramento de nossa relação com as telas. Lembremo-nos que estas, em sua versão audiovisual, surgiram no cinema, adentraram às casas ocupando as salas de estar junto aos televisores, que passaram à intimidade dos quartos, e hoje nos acompanham nos bolsos, em contato frequente com nossos corpos. Difícil imaginar, antes dos smartphones, a possibilidade de tantas imagens tão próximas a nós.

E as telas dos smartphones, cada vez maiores e com melhor resolução, não só eliminaram os teclados físicos por meio do touchscreen, que coloca as imagens ao alcance e sob o controle da

3. Num certo sentido, quando abordamos tanto o universo do audiovisual como o universo da informática, estamos lidando com derivações da técnica fotográfica, ideia esta bastante desenvolvida por Vilém Flusser por meio de seus conceitos de imagem técnica, informação, programa e superficialidade (Flusser, 2002; 2008). 
ponta dos dedos ${ }^{4}$, como parecem ter assumido um espaço cada vez mais definitivo para o destino da fotografia em sua versão eletrônica.

Foi a empresa Samsung, em 2000, que ensaiou a junção do celular a uma câmera fotográfica ${ }^{5}$. Tratava-se do primeiro modelo de celular que carregava uma câmera de 0,35 megapixels acoplada ao aparelho. Meses depois, a japonesa Sharp inaugurou o universo dos celulares que tinham uma câmera embutida, o que possibilitava, pela primeira vez, o compartilhamento digital imediato da imagem. Ao lado da câmera, o aparelho dispunha de uma pequena superfície espelhada que possibilitava tirar fotos de si próprio observando uma prévia do resultado (já era possível fazer uma selfie e compartilhá-la instantaneamente, por exemplo).

Apesar de, a partir de então, tornar-se cada vez mais comum a presença de câmeras em celulares, seria em 2007, com o lançamento do iPhone, que essa hibridização tomaria seus devidos contornos. Este dispositivo, da empresa estadunidense Apple, passaria a ser um modelo a ser seguido pelos smartphones, a nova e mais adequada denominação para os celulares portadores de múltiplas funções, dentre elas, a presença obrigatória de câmeras fotográficas (atualmente, é possível até observar a presença de três câmeras, como nas recentes versões do iPhone).

Foi a partir desse modelo, o qual favorecia e facilitava a instalação de aplicativos diversos advindos da web, que a câmera fotográfica passou a realmente se aproximar da telemática, isto é, do universo informativo que aliava telecomunicações e informática. A proximidade chegou a tal ponto que os aplicativos conectados à internet passaram a ter acesso direto à câmera, e a fotografia poderia ser praticamente capturada on-line.

Um breve retrospecto que demonstra haver, em curso, um visível deslocamento do interesse pela câmera para o interesse pela tela conectada à rede, fazendo do compartilhamento um importante elemento de constituição do processo fotográfico, praticamente o "segundo clique da fotografia", tal como reconhecido por Silva Jr.:

de maneira semelhante ao clique, que se configurou como um atributo da fotografia diante da percepção do instante; o botão e ato de compartilhar conformam um conjunto de saberes onde defendemos ser este o hiperatributo que agrega à fotografia atual a lógica do segundo clique. Se for clicada, mas não circulada, a imagem produzida carece de uma existência completa, pois não sincroniza-se com os demais valores pertença da produção simbólica com que convive (Silva Jr., 2015, p.8).

Assim posto, torna-se fundamental, portanto, também se levar em consideração a recente trajetória desses ambientes de circulação, as redes, que vêm edificando um espaço cada vez mais importante na determinação de aspectos de uma prática fotográfica nos dias atuais.

\section{Da grande rede às pequenas grandes redes}

Walter Benjamin não teve a oportunidade de acompanhar o desenvolvimento de um projeto que mudaria não só a história da fotografia, como a história da humanidade: a internet.

4. Cumpre-nos também lembrar a perspicaz contribuição de Flusser, que, ainda na década de 1980, já afirmava que "o homem, nesse future de coisas imateriais, garantirá sua existência graças às pontas dos dedos (Flusser, 2008, p. 63).

5. Hill, S. From J-Phone to Lumia 1020: A complete history of the camera phone. Disponível em www.digital trends.com/mobile/camera-phone-history. Acesso em 18 abr. 2017. 
A essência da rede que temos hoje surgiu em meados de 1960, quando o governo estadunidense investiu numa rede de comunicação militar que fosse descentralizada o suficiente para sobreviver a um ataque em alguma unidade específica, por parte da União Soviética (Castells, 1999). Essa rede de unidades autônomas trouxe o que talvez seja a característica mais fundamental da internet: a horizontalidade. Depois de abandonado o projeto militar em 1990, a internet passou a ser desenvolvida "de forma múltipla por pessoas, setores e inovadores que queriam que fosse um instrumento de comunicação livre" (Castells, 2003, p.4), e portanto, se manteve horizontal.

O crescimento exponencial da rede foi simultâneo ao desenvolvimento e proliferação dos computadores pessoais em todo o mundo, o que possibilitou que a internet acabasse "convertendo-se no coração articulador dos distintos meios, da multimídia" (Castells, 2003, p.17), já que permite a canalização e a interconexão da informação onde quer que seja. Importante ressaltar que, diferentemente dos meios de comunicação até então estabelecidos, como a imprensa, a televisão ou o rádio, com este reordenamento do fluxo e da distribuição de informação, não mais necessariamente o centro move e a periferia é movida. Estabelece-se um circuito multidirecional nas redes, "sem a hierarquia opressiva do unidirecionalismo" (Sodré, 2014, p. 86). Este é um marco para uma mudança no paradigma da circulação da imagem, uma vez aberta a possibilidade para que ela, pela primeira vez, circule horizontalmente no universo digital.

Uma vez estabelecida essa grande rede mundial de computadores, as ferramentas de comunicação em seu interior é que passaram a ser desenvolvidas. Assim como os aparelhos fotográficos dependiam de conhecimento técnico para o uso da tecnologia, os computadores também exigiam certa habilidade para que uma pessoa pudesse se comunicar via internet. A internet, que antes era de uso exclusivo de militares, cientistas e pesquisadores, tornou-se acessível ao passo que foram surgindo tais ferramentas facilitadoras, assim como é o e-mail, que ainda mantém os mesmos moldes de quando foi lançado.

Muitos consideram esta comunicação de atores sociais via internet como a primeira rede social de grande escala na internet, já que "uma rede social é definida como um conjunto de dois elementos: atores (pessoas, instituições ou grupos; os nós da rede) e suas conexões (interações ou laços sociais)" (Recuero, 2009, p. 24), e que, portanto, a própria concepção da internet que possibilitou a conexão de atores sociais já poderia se caracterizar como uma rede social.

No entanto, o senso comum costuma classificar como redes sociais apenas os sites de redes que atuam como suportes para a exposição e interação entre atores a partir da construção de um perfil online (Recuero, 2009), tais como blogs, chats, e plataformas como os famosos Orkut, Facebook, Linkedin, Instagram, Snapchat, entre outros. Cada uma dessas ferramentas de comunicação em rede oferece uma interface, um propósito, um modelo de navegação, que cumprem diferentes expectativas e geram diferentes experiências nas redes.

Os primeiros grandes sites de redes sociais foram lançados em 1995, como é o caso do ClassMates.com, que tinha o intuito de reunir colegas de escolas e universidades, e, em 1997, quando a America Online lançou o Instant Messenger, pioneiro na troca de mensagens instantâneas online ${ }^{6}$. Mas foi só em 2004 que surgiu a ideia da WEB 2.0, que introduziu mais fortemente a prática

6. Daquino, F. A história das redes sociais: como tudo começou. Disponível em www.tecmundo.com.br/redessociais/33036-a-historia-das-redes-sociais-como-tudo-comecou.htm. Acesso em 18 de abr. 2017. 
de interação nos moldes do que conhecemos hoje, com curtidas e comentários. Nesse mesmo ano foram lançadas as plataformas do Orkut e do Facebook, que atualmente é a mais utilizada no mundo.

Outro marco fundamental, que modificou tanto a experiência dos atores sociais na web quanto o modelo de circulação de informação - e de imagens - aconteceu em 2009, quando o buscador da Google deu início a um modelo de navegação personalizado ${ }^{7}$. Com a ajuda de algoritmos, o navegador passou a identificar as predileções de cada usuário, baseado em seu histórico de buscas, para lhe fornecer os links que, provavelmente, mais o interessavam.

Essa mesma lógica passou a operar no Facebook no ano seguinte ${ }^{8}$. Os interesses pessoais, as preferências e as predileções, sistematicamente programados pelos algoritmos, passaram a definir qual o conteúdo seria visualizado na plataforma online. Os perfis dos atores deixaram de receber, em ordem cronológica no feed de notícias, o conteúdo que os outros nós conectados ao seu era publicado na rede.

O ordenamento cronológico deu lugar ao ordenamento afetivo. Somente aquele conteúdo que fosse classificado dentre as predileções do usuário é que iriam alcançá-lo. Em 2016, o Twitter ${ }^{9}$, lançado dez anos antes, e o Instagram ${ }^{10}$, lançado em 2010 , também passaram a funcionar obedecendo a máxima "veja o que te interessa primeiro", justificando que não haveria tempo hábil para que o ator visualizasse todo o conteúdo publicado por seus pares na rede e, portanto, seria necessária uma pré-seleção do que deveria ser visualizado primeiro. Hoje essa lógica opera em boa parte dos sites na internet, como os buscadores, sites de venda, de notícias, de entretenimento, etc.

Os algoritmos, nesse caso, são determinantes para a circulação de imagens dentro dessa rede horizontalizada (nas palavras de Malini, os algoritmos são responsáveis pela editoração do mundo ${ }^{11}$ ). Cria-se, automaticamente, pequenas redes, grupos e circuitos baseados em afinidades. Cercado por seus próprios interesses, o ator se vê numa atrativa zona de conforto, um ambiente intimista, confortável e protegido, ao alcance da ponta dos dedos. Uma zona de conforto que era almejada "um pouco como condomínios distantes do centro das cidades, circundados por muros, guardas armados e câmeras em circuito fechado, onde as pessoas vivem num tipo de mundo imaginário, sem controvérsias, sem conflitos, sem se expor às diferenças" (Bauman, 2016).

A facilidade e a praticidade dentro desse ambiente confortável favorecem a reprodução em grande escala. É possível dizer que aquela velha prática de se passar uma fotografia de mão em mão evoluiu. É uma nova característica de grande impacto. Não somente "a concepção das

7. Horling, B e Kulick, M. Personalized Search for everyone. Disponível em https://googleblog.blogspot. com.br/2009/12/personalized-search-for-everyone.html. Acesso em 18 de abr. 2017.

8. Schonfeld, E. Zuckerberg: "We Are Building A Web Where The Default Is Social". Disponível em https://techcrunch.com/2010/04/21/zuckerbergs-buildin-web-default-social/. Acesso em 18 de abr. 2017.

9. Jahr, M. Never miss important Tweets from people you follow. Disponível em https://blog.twitter.com/ 2016/never-miss-important-tweets-from-people-you-follow Acesso em 18 de abr. 2017.

10. Instagram. See the Moments You Care About First. Disponível em http://blog.instagram.com/post/1411 07034797/160315-news. Acesso em 18 de abr. 2017.

11. Córtex: Mapas de rede, Trends de Rua e a Política na Era do Perfil. Um passeio com Fábio Malini. Produção de Estúdio Fluxo. Entrevistador: Bruno Torturra. São Paulo, 2016. Disponível em www.youtube.com/ watch?v=JdY0HfW4ygQ. Acesso em 14 de abril de 2017. 
grandes obras se modificou simultaneamente com o aperfeiçoamento das técnicas de reprodução" (Benjamin, 1994, p. 104), como já reconhecia Benjamin, como hoje a própria concepção da ação humana mudou diante das câmeras.

Com o advento dos smartphones, que combinam a evolução da prática fotográfica e a evolução da internet, as imagens passaram a circular de tela em tela numa escala exponencial, e com objetos e situações fotografáveis nunca antes explorados. A aptidão da fotografia para imagens efêmeras e secretas, tal como apontara Benjamin, agora ganha corpo num ambiente em constante conexão.

\section{A imagem conectada}

Ao longo destes já quase duzentos anos de trajetória das imagens fotográficas, diversas foram as formas e estratégias de conexão entre fotografias. Da diagramação de peças gráficas, sobretudo as páginas das revistas ilustradas ou jornais, que operavam com a construção de narrativas costuradas por textos, às paginas de sites na web refinadas pela ascensão do design multimidiático- e sem nos esquecermos dos álbuns de família ou até do próprio cinema, que, grosso modo, estruturou-se exatamente pelo encadeamento de imagens de natureza fotográfica-, é possível afirmar que uma ideia de conexão entre as imagens sempre esteve circundando a prática fotográfica.

No entanto, há certas especificidades promovidas pelas redes sociais quando pensamos nessa prática conectiva da fotografia. No que tange ao aspecto do encadeamento, por exemplo, há a possibilidade de uma forma de conexão que se difere radicalmente das formas anteriores: redes como o Instagram e Snapchat operam com uma evidente aleatoriedade na construção de suas narrativas, e as fotografias, apesar de estruturadas em timelines, isto é, linearmente, criam significações nãolineares e imprevisíveis. Imagens que se conectam fortuitamente, advindas de diversas fontes e a qualquer momento, e que, assim, vão compondo um espaço de circulação que favorece uma certa liberdade de produção.

Outro importante aspecto observado nas redes citadas (que, cabe lembrar, são as duas redes fotográficas mais evidentes da atualidade), é a crescente valorização de práticas que se servem da efemeridade da imagem digital, uma vez que permitem atribuir duração à circulação das fotografias, em que estas desaparecem após 24 horas depois da postagem. Também essas quebras de permanência e durabilidade acabam por reforçar a instrumentalização da fotografia numa direção muito mais livre e despojada.

Em síntese, as redes sociais vêm se tornando cada vez mais uma extensão da prática fotográfica, que impactam e interferem nas próprias motivações para a produção da imagem.

Para ficarmos num único exemplo concreto, basta observarmos como o retrato fotográfico, o gênero mais representativo e que melhor remunerava os fotógrafos durante a primeira expansão do mercado de fotografia, tal qual relatado por Benjamin, agora ganha uma outra dinâmica por meio das selfies, este tipo de retrato que, segundo o tradicional dicionário inglês, Oxford, que a elegeu como "a palavra do ano" de 2013, é definida a partir de sua conexão com a rede: "a photograph that one has taken of oneself, typically one taken with a smartphone or webcam and shared via social media" (Oxford, 2017). Silva Jr. sustenta:

A ampliação desses cenários de circulação, principalmente em redes sociais como Instagram

e Facebook, deflagra através do hiperatributo uma economia da atenção diferenciada, onde o 
pertencimento é destacado. A ênfase, portanto, recai em um grau de alta exposição do self através de imagens. Ver e ser visto, sobreposto a onipresença de câmeras conectadas, móveis acionam o pertencimento simbólico como atributo desta fotografia contemporânea em seu uso cotidiano e vernacular (Silva Jr., 2015, p.9).

As selfies dão vazão, portanto, a esta necessidade de se destacar nesta nova "economia de atenção" que é propulsionada pelas dinâmicas em rede. A possibilidade de uma construção de personalidade pela construção de uma imagem se torna uma necessidade nesses ambientes. $\mathrm{O}$ consagrado carte-de-visite, do final do século XIX, não é somente uma opção, mas agora, travestido de "foto de perfil", torna-se quase que uma obrigatoriedade num contexto em que a construção da subjetividade está envolvida por um ambiente alto grau de exposição constante.

Por outro lado, e a reboque desta forma contemporânea de manifestação do self pela imagem, assistimos também a um exercício constante de visitação ao gênero fotográfico do retrato.

Quando Benjamin aborda o retrato constrangedor de Kafka ainda menino, fruto de uma certa solenidade inerente aos protocolos iniciais da prática social da fotografia, há de se notar ali uma certa ausência de liberdade, manifestada pela própria expressão do retratado, configurando uma espécie de projeção das limitações técnicas da fotografia sobre o personagem à frente da câmera, cuja postura acabava por representar todas as dificuldades inerentes às laboriosidades dos processos iniciais. Mesmo nos retratos de Sander, independentemente do valor inestimável de sua taxonomia fotográfica em chapas que mostra o rosto humano com uma "significação nova e incomensurável" (Benjamin, 1994, p. 102), essa solenidade técnica é proeminente. De certa forma, é possível afirmar que tal solenidade não circunda a atual produção de retratos despojados que circulam nas redes. 


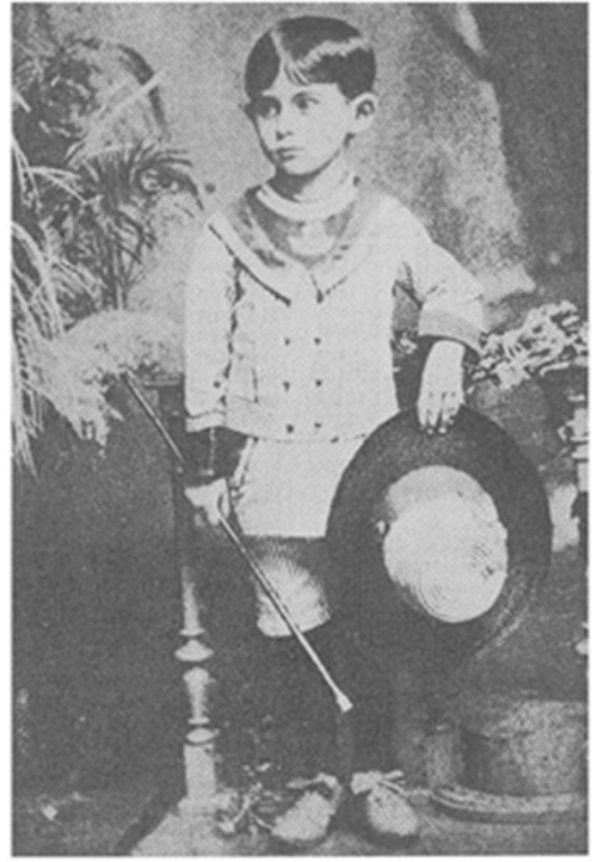

Figura 1. Retrato de Kafka ainda menino e a manifestação de uma solenidade técnica.

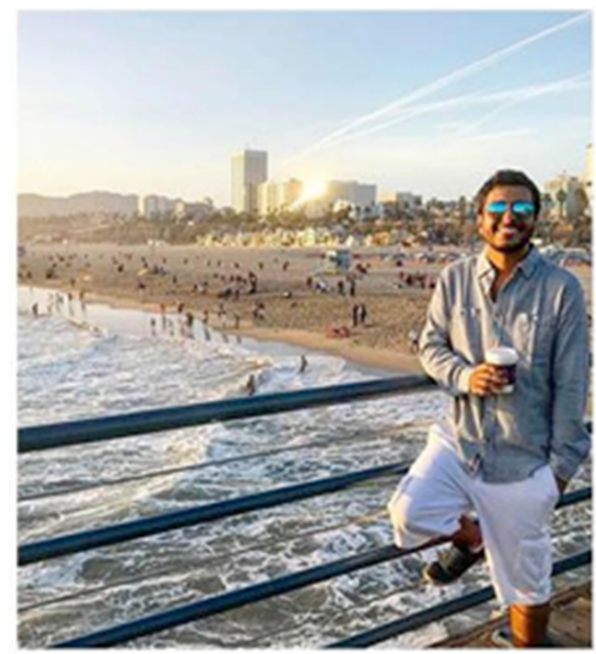

Figura 2. Exemplo de retrato contemporâneo, evidenciando liberdade e despojamento técnico.

As fotografias eram sim "paisagens impregnadas de estados afetivos"(Benjamin, 1994, p. 94), mas talvez tenhamos somente agora a devida liberdade para priorizar tais afetos na produção das imagens. 
É provável que estas primeiras imagens desta ainda pequena história da fotografia nas redes sociais não tenham tanta vocação para serem "belas e inabordáveis", da forma como Benjamin definiu aquelas dos primeiros passos da técnica no século XIX; mas possuem um valor que talvez esteja encoberto pelo despojamento técnico que favorece o excesso de imagens e retira destas o seu aspecto de solenidade.

Afinal, para Benjamin, "apesar de toda a perícia do fotógrafo e de tudo que existe de planejado em seu comportamento, o observador sente a necessidade irresistível de procurar nessa imagem a pequena centelha do acaso, do aqui e agora"(Benjamin, 1994, p.94).

De certa forma, é exatamente esta "centelha" que hoje é trazida à tona e evidenciada, quando não imposta, pela instantaneidade de produção e circulação das redes sociais, o que favorece, enfim, o que o autor denominou como a vocação da fotografia para servir a "todos os aspectos da atividade humana", sobretudo tendo em vista a inevitabilidade da conexão, esta um pano de fundo que funciona como um elemento articulador e decisivo para a atuação da imagem fotográfica contemporânea.

\section{Referências}

Benjamin, W. (1994). Pequena história da fotografia. Obras Escolhidas, Vol I-Magia e Técnica, Arte e Política. São Paulo: Editora Brasiliense.

Castells, M. (2003). Internet e sociedade em rede. In D. Moraes (org.), Por uma outra comunicação. Rio: Record.

Castells, M. (1999). Sociedade em rede. São Paulo: Paz e Terra.

CórTex: Mapas de rede, Trends de Rua e a Política na Era do Perfil. Um passeio com Fábio Malini. Produção de Estúdio Fluxo. Entrevistador: Bruno Torturra. São Paulo, 2016. Disponível em www.youtube.com/watch?v=JdY0HfW4ygQ. Acesso em 14 de abril de 2017.

Daquino, F. (s.d.). A história das redes sociais: como tudo começou. Disponível em www.tecmund o.com.br/redes-sociais/33036-a-historia-das-redes-sociais-como-tudo-comecou.htm. Acesso em 18 de abr. 2017.

Flusser, V. (2008). Universo das imagens técnicas: o elogio da superficialidade. São Paulo: Annblume.

Flusser, V. (2002). Filosofia da caixa preta. Rio de Janeiro: Relume Dumará.

Horling, B \& Kulick, M. (s.d.). Personalized Search for everyone. Disponível em https://googleblo g.blogspot.com.br/2009/12/personalized-search-for-everyone.html. Acesso em 18 de abril de 2017.

OXFORD. Definition of selfie in english. Disponível em https://en.oxforddictionaries.com/definitio n/selfie. Acesso em 14 de abril de 2017.

Recuero, R. (2009). Redes sociais na internet. Porto Alegre: Sulina.

Schonfeld, E. (s.d.). Zuckerberg: "We Are Building A Web Where The Default Is Social". Disponível em https://techcrunch.com/2010/04/21/zuckerbergs-buildin-web-default-social/. Acesso em 18 de abril de 2017. 
Silva Jr., A. (2015). O segundo clique da fotografia: entre o registro do instante e o instante compartilhado. Trabalho apresentado ao GP Fotografia, XIV Encontro dos Grupos de Pesquisas em Comunicação, evento componente do XXXVIII Congresso Brasileiro de Ciências da Comunicação, Rio de Janeiro. Disponível em http://portalintercom.org.br/anais/nacional2015/r esumos/R10-1924-1.pdf. Acesso em 19/04/2017.

Sodré, M. (2014). A ciência do comum. Petrópolis: Vozes. 